(Supporting Information)

\title{
Hierarchical Amplification of Macromolecular Helicity in a Lyotropic Liquid Crystalline Charged Poly(phenylacetylene) by Nonracemic Dopants in Water and Its Helical Structure
}

Kanji Nagai, ${ }^{\dagger}$ Koichi Sakajiri, ${ }^{*,+},{ }^{\prime}$ Katsuhiro Maeda, ${ }^{\dagger}$ Kento Okoshi, ${ }^{*}$ Takahiro Sato, ${ }^{*, y}$ and Eiji Yashima* ${ }^{*, t,+}$

${ }^{\dagger}$ Department of Molecular Design and Engineering, Graduate School of Engineering, Nagoya University, Chikusa-ku, Nagoya 464-8603, Japan

${ }^{\star}$ Yashima Super-structured Helix Project, Exploratory Research for Advanced Technology (ERATO), Japan Science and Technology Agency (JST), Creation Core Nagoya 101, 226622 Anagahora, Shimoshidami, Moriyama-ku, Nagoya 463-0003, Japan

${ }^{5}$ Department of Macromolecular Science, Osaka University, 1-1 Machikaneyama-cho, Toyonaka, Osaka 560-0043, Japan

${ }^{\S}$ Present address: Department of Chemistry, Faculty of Engineering, Gifu University, Yanagido, Gifu 501-1193, Japan

\section{Materials and Instruments (Figures S1 and S2)}

Materials. Deionized distilled water was used in all the experiments unless otherwise noted. Optically active compounds were obtained from Aldrich or Tokyo Kasei (TCI, Tokyo, Japan). $(S)$ - and $(R)-2$ and $(S)$-3 were prepared by the reaction of the corresponding carboxylic acids with aqueous $\mathrm{NaOH}$. The stereoregular cis-transoidal poly1 was prepared by the polymerization of the corresponding monomer with a rhodium catalyst according to the previously reported method. ${ }^{1-3}$ The resulting polymer was quantitatively converted to its $\mathrm{HCl}$ salt (poly-1-HCl) with aqueous $\mathrm{HCl}$, followed by precipitation into acetone; its number-average molecular weight $\left(M_{\mathrm{n}}\right)$ and molecular weight distribution $\left(M_{\mathrm{w}} / M_{\mathrm{n}}\right)$ were $3.4 \times 10^{5}$ and 2.21 , respectively, as determined by size exclusion chromatography (SEC). ${ }^{2,3}$ The $M_{\mathrm{n}}$ and $M_{\mathrm{w}} / M_{\mathrm{n}}$ were also estimated by atomic force 
microscopy $(\mathrm{AFM})^{4}$ and were $2.36 \times 10^{5}$ and 1.43 , respectively (for more details, see Section 4). The stereoregularity of the original poly-1 and poly-1-HCl was investigated by ${ }^{1} \mathrm{H}$ NMR and laser Raman spectroscopies. ${ }^{1-3,5}$ Previously, we reported that the stereoregularity of poly-1- $\mathrm{HCl}$ could not be determined by its ${ }^{1} \mathrm{H}$ NMR spectrum in $\mathrm{D}_{2} \mathrm{O}$ because of the broadening of the main chain protons even at $80{ }^{\circ} \mathrm{C}$, probably due to the rigidity of the polymers' main chains. ${ }^{2,3}$ However, the ${ }^{1} \mathrm{H}$ NMR spectrum of the original poly-1 in $\mathrm{CD}_{3} \mathrm{CN}$ in the presence of $\mathrm{CF}_{3} \mathrm{CO}_{2} \mathrm{D}$ showed a sharp singlet centered at $5.76 \mathrm{ppm}$, due to the main chain proton, indicating that poly-1 possesses a highly cis-transoidal, stereoregular structure (Figure S1). The exact cis content was estimated to be $96 \%$ by using the following equation based on the literature method for poly(phenylacetylene $)^{5, \mathrm{f}}$ :

$$
\% \text { cis }=\left[\mathrm{A}_{5.76} /\left(\mathrm{A}_{\text {total }} / 21\right)\right] \times 100
$$

where $\mathrm{A}_{5.76}$ and $\mathrm{A}_{\text {total }}$ represent the area of the main chain proton resonance at $5.76 \mathrm{ppm}$ and the total area of all proton resonances of poly-1 in its ${ }^{1} \mathrm{H}$ NMR spectrum (Figure S1). Poly1- $\mathrm{HCl}$ was then converted to poly-1 by treatment with aqueous $\mathrm{NaOH}$ and its ${ }^{1} \mathrm{H} \mathrm{NMR}$ spectrum of the recovered poly-1 was measured under the same conditions. The recovered poly-1 exhibited the identical spectrum as that of the original poly-1, indicating that poly-1$\mathrm{HCl}$ also has a highly cis-transoidal structure. The Raman spectra of poly-1 and poly-1$\mathrm{HCl}$ (Figure S2) also support this conclusion; poly-1 and poly-1-HCl showed characteristic vibrations in the cis polyacetylenes, while those in the trans polyacetylene were scarcely observed. $^{6}$

Consequently, the poly-1-HCl is a highly stereoregular cis-transoidal (cis content > $96 \%)$ polymer. We also carefully examined the thermal stability of poly-1-HCl with $(R)-2$ (ref. 19 in the text) and confirmed that the polymer was quite stable in water. 


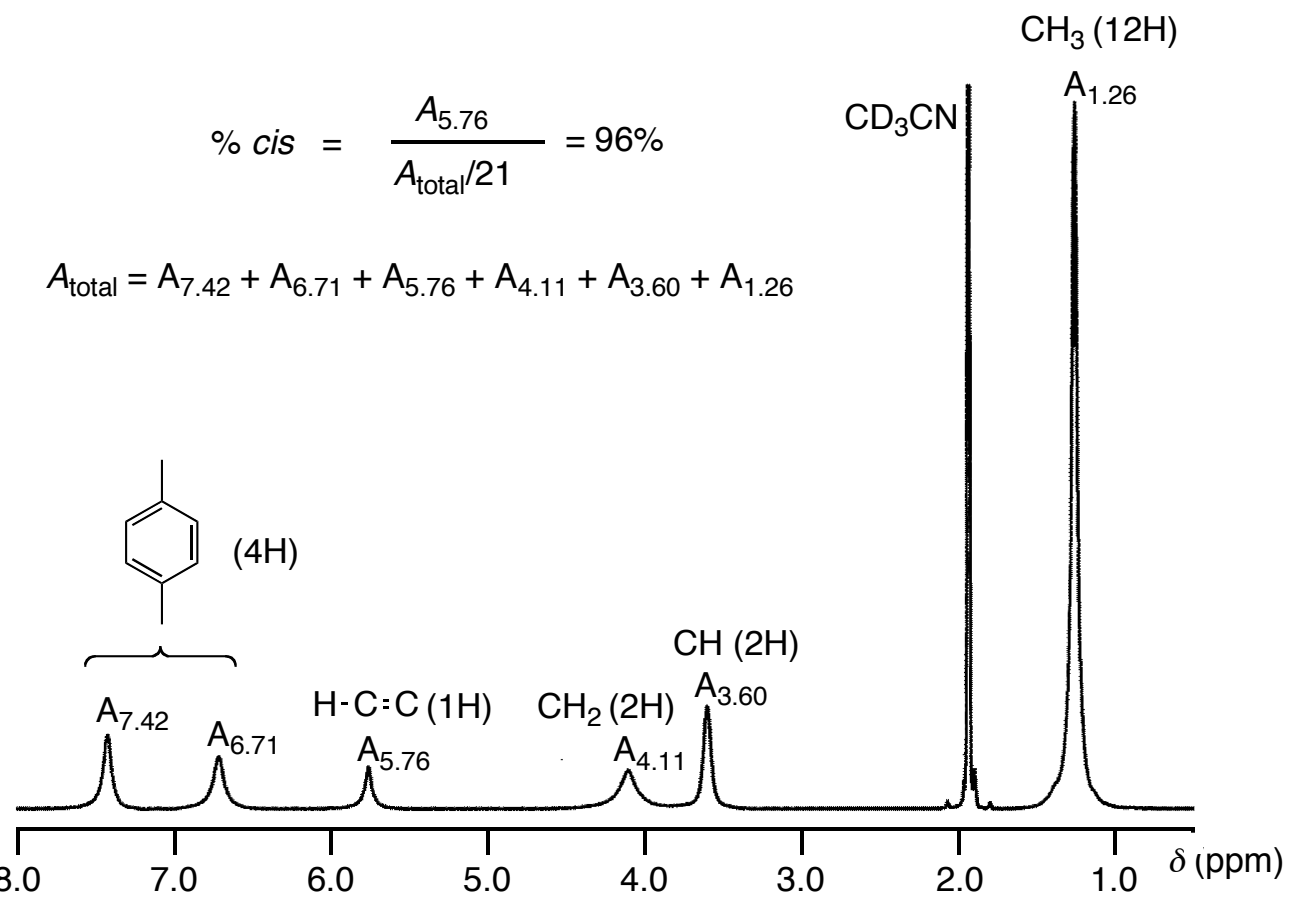

Figure S1. ${ }^{1} \mathrm{H}$ NMR spectrum of poly-1 in $\mathrm{CD}_{3} \mathrm{CN}$ with $\mathrm{CF}_{3} \mathrm{CO}_{2} \mathrm{D}\left(\left[\mathrm{CF}_{3} \mathrm{CO}_{2} \mathrm{D}\right] /[\right.$ poly-1] $=$ 2) at $60{ }^{\circ} \mathrm{C}$.

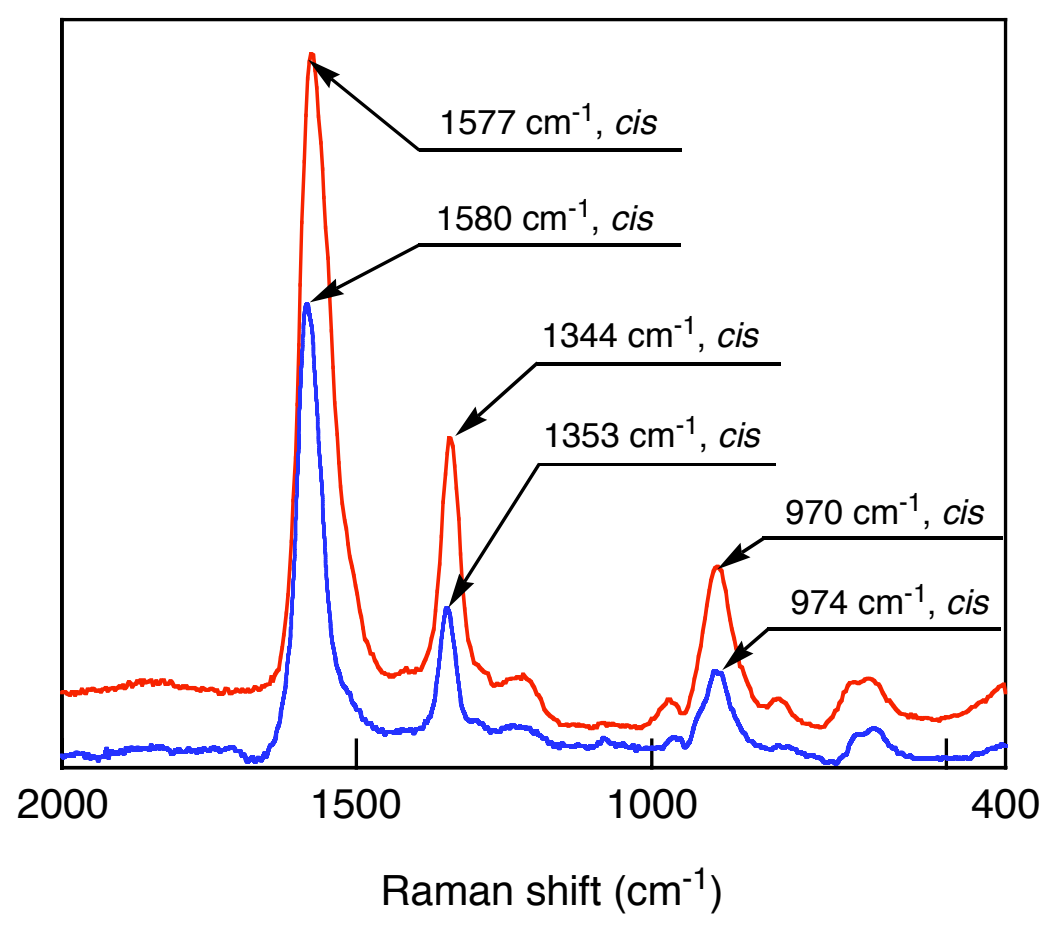

Figure S2. Laser Raman spectra of poly-1 (red line) and poly-1-HCl (blue line). 
Instruments. $\quad{ }^{1} \mathrm{H}$ NMR spectra were taken using a Varian VXR-500S spectrometer operating at $500 \mathrm{MHz}$ for ${ }^{1} \mathrm{H}$. Laser Raman spectra were measured on a Jasco NRS-1000 spectrophotometer. Absorption (Jasco V-570, Hachioji, Japan) and CD (Jasco J-725) spectra were measured in water in a $1.0-\mathrm{mm}$ quartz cell at $25{ }^{\circ} \mathrm{C}$. AFM measurements were performed on a Nanoscope IIIa microscope (Veeco, Santa Barbara, CA) in air at ambient temperature $\left(20-25^{\circ} \mathrm{C}\right)$ with standard silicon tips $(\mathrm{NCH}-10 \mathrm{~V})$ in the tapping mode. AFM images were measured at the resonance frequency of the tips with $125-\mu \mathrm{m}$-long cantilevers $(200-300 \mathrm{~Hz})$ and a spring constant of approximately $40 \mathrm{~N} / \mathrm{m}$. All the images were collected with the maximum available number of pixels (512) in each direction. The scanning speed was at a line frequency of $1.0 \mathrm{~Hz}$. The effective silicon tip radii were estimated with Au colloids (5 nm; ICN Biomedicals, Inc., Aurora, OH) as imaging standards $^{7}$ and were 5-10 nm. X-ray measurements were performed with a Rigaku RAXIS VII detector system equipped with a Rigaku FR-E rotating-anode generator with confocal mirror monochromated $\mathrm{Cu} \mathrm{K} \alpha$ radiation $(0.15418 \mathrm{~nm})$ focused through a $0.5 \mathrm{~mm}$ pinhole collimator, which was supplied at $45 \mathrm{kV}$ voltage and $45 \mathrm{~mA}$ current, equipped with a flat imaging plate of specimen-to-plate distance $300 \mathrm{~mm}$. Elemental analysis was performed by the Nagoya University Analytical Laboratory in School of Engineering. The solution $\mathrm{pH}$ was measured with a B-211 $\mathrm{pH}$ meter (Horiba, Japan). The molecular modeling and molecular mechanics (MM) calculation were performed on the program system Ms Modeling software (version 3.1, Accelrys Inc., San Diego, CA).

\section{Absorption and CD Measurements in Dilute Solution (Figures 1 and S3)}

The concentration of poly-1-HCl was calculated on the basis of the monomer units and was $1.0 \mathrm{mg} / \mathrm{mL}$ in dilute solution unless otherwise stated. On the complexation of poly-1$\mathrm{HCl}$ with optically active acids, a stock solution of poly-1- $\mathrm{HCl}(2.0 \mathrm{mg} / \mathrm{mL})$ in water was 
prepared in a 5-mL flask equipped with a stopcock. A $500 \mu \mathrm{L}$ aliquot of the poly-1-HCl solution was transferred to a vessel equipped with a screwcap using a micropipette (Nichiryo Nichipet EX, Japan). An appropriate amount of $(R)$ - or $(S)$-acid was added to the vessel and the solution was diluted with water to keep the poly-1-HCl concentration at 1.0 $\mathrm{mg} / \mathrm{mL}$ and absorption and CD spectra were measured. The changes in the ICD intensity of poly-1-HCl with respect to the ee of $2(1 \%<$ ee $<100 \%$, nonlinear effects) were investigated as follows. ${ }^{2}$ The molar ratio of $\mathbf{2}$ to the monomer units of poly-1-HCl was held constant at 0.1 . Stock solutions of the $(S)$ - and $(R)-2(0.93 \mathrm{mg} / \mathrm{mL})$ in water were prepared in separate $25-\mathrm{mL}$ flasks. The $0.50 \mathrm{~mL}$ aliquots of the poly-1- $\mathrm{HCl}$ solution $(2.0 \mathrm{mg} / \mathrm{mL})$ were transferred to eleven 1-mL flasks equipped with stopcocks. Aliquots of the stock solutions of $(S)$ - and $(R)-2$ were then placed in the flasks so that the percent ee of the mixtures ( $S$-rich) was $1,5,10,15,20,25,40,50,60,75$ and 100, and the solutions were finally diluted with water to maintain the poly-1- $\mathrm{HCl}$ concentration at $1.0 \mathrm{mg} / \mathrm{mL}$. After mixing the solutions, the $\mathrm{CD}$ and absorption spectra were measured for each flask (Figures $1 \mathrm{~A}-1 \mathrm{C}$ and Table 1$)$. The maximum $\Delta \varepsilon_{2 n d}$ value was estimated to be -17.2 from the titration results with $(S)$-2 in dilute water. The $\Delta \varepsilon_{2 \text { nd }}$ values were plotted versus the inverse $[(S)-2] /[$ poly-1-HCl] and the data points almost obey a straight line with a positive slope. From the intercept, the maximum $\Delta \varepsilon_{2 \text { nd }}$ at $25^{\circ} \mathrm{C}$ in water was determined (Figure S3). 


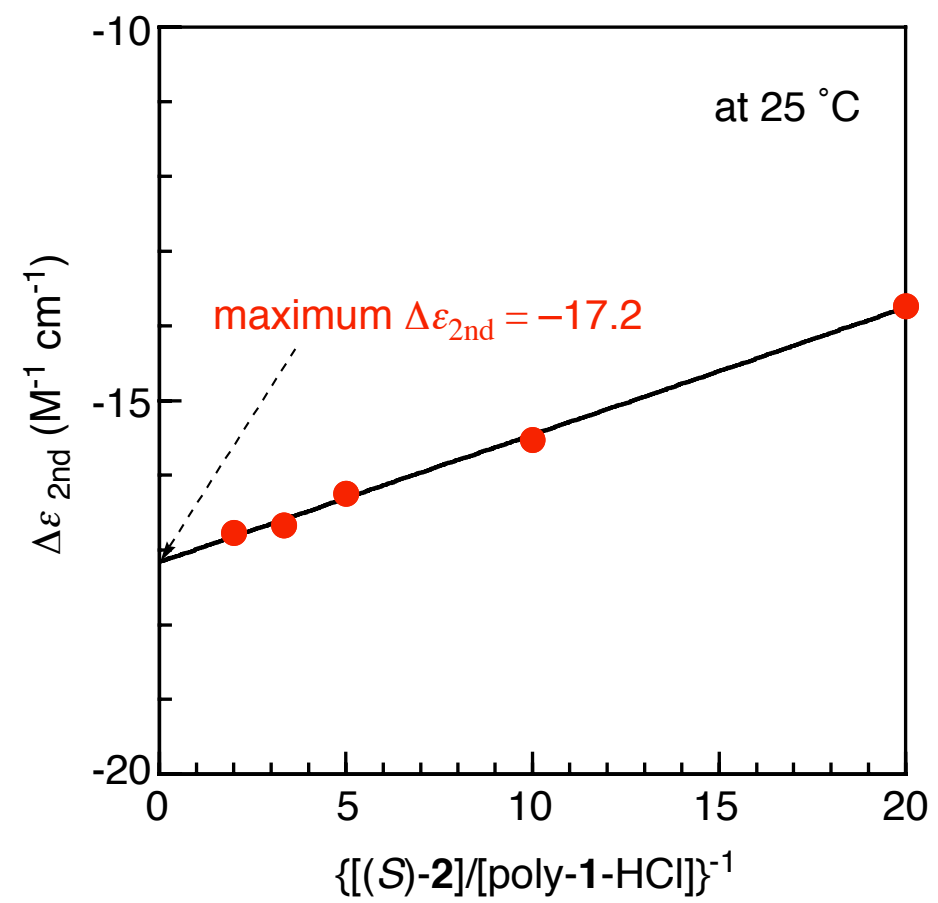

Figure S3. Plots of the ICD intensity $\left(\Delta \varepsilon_{2 n d}\right)$ of poly-1-HCl $([$ poly-1-HCl $]=1 \mathrm{mg} / \mathrm{mL})$ versus $\{[(S)-\mathbf{2}] /[\text { poly-1-HCl }]\}^{-1}$ in water at $25^{\circ} \mathrm{C}$.

\section{Preparation of Liquid Crystal Samples for Polarized Microscopy Studies (Figure} S4)

The concentrated poly-1-HCl (5 mg) solution in water (20 wt \%; (weight of total polymer $) /[($ weight of total polymer $)+($ weight of water $)])$ was prepared in a 2 -mL test tube, for the nematic liquid crystalline poly-1-HCl. After the polymer was completely dissolved to give a clear and homogeneous solution, the solution was transferred to a 1.0-mm (i.d.) glass capillary by pipet and the ends then sealed. The cholesteric solutions were prepared in the same way using a $20 \mathrm{wt} \%$ poly-1- $\mathrm{HCl}$ solution in water in the presence of appropriate amounts of optically active acids. The samples were left at ambient temperature (20-25 ${ }^{\circ} \mathrm{C}$ ) for one hour or days until stable fingerprint textures were obtained. The fingerprint textures showing the retardation lines for the cholesteric LCs were observed using a 
NIKON E600POL polarized microscope. The fingerprint spacings, which are equal to the half pitch of the cholesteric helical structure, were measured by comparing it to a photograph of a standard microscopic ruler. The average cholesteric pitches $(p)$ were estimated on the basis of an evaluation of about 30 fingerprint spacings. The maximum $q_{\mathrm{c}}$ $(2 \pi / p)$ value was determined to be $1.55 \mu^{-1}$ from the titration results with $(S)-2$ in a concentrated water solution $(20 \mathrm{wt} \%)$ at ca. $25^{\circ} \mathrm{C}$. The $q_{\mathrm{c}}$ values were plotted versus the inverse $[(S)-2] /\left[\right.$ poly-1-HCl]. The $q_{\mathrm{c}}$ value reached an almost constant value at 0.05 to 0.3 equiv of $(S)$-2. From the intercept, the maximum $q_{\mathrm{c}}$ was determined (Figure S4).

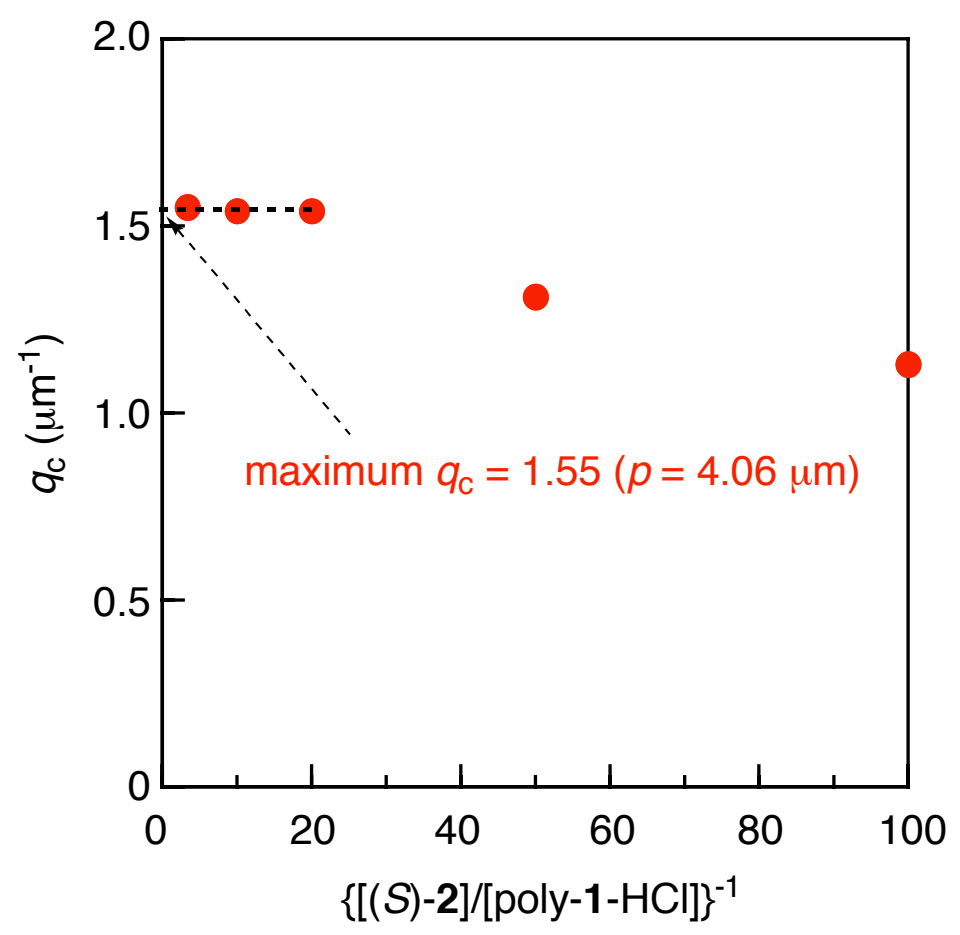

Figure S4. Plots of the $q_{\mathrm{c}}$ of poly-1-HCl ([poly-1-HCl] $=20 \mathrm{wt} \%$ ) versus $\{[(S)-2] /[$ poly1- $\mathrm{HCl}]\}^{-1}$ in concentrated water solution at ca. $25^{\circ} \mathrm{C}$.

\section{Molecular Length (Weight) and Its Distribution Measurements (Figure S5)}

AFM was used to estimate the molecular length (weight) of poly-1-HCl and its 
distribution. A stock solution of poly-1 $(0.0025 \mathrm{mg} / \mathrm{mL})$ in $0.015 \mathrm{M}$ aqueous $\mathrm{HCl}$ was prepared. An eight $\mu \mathrm{L}$ sample of the stock solution was dropped on a freshly cleaved mica, the solution was blown off simultaneously with a stream of nitrogen, then the mica substrate was dried in vacuo overnight to measure the AFM images in the tapping-mode (Figure S5A). Under a dilute condition, single molecules of poly-1-HCl could be observed, and such a molecular resolution allowed direct measurements of the average molecular length of poly-1-HCl. ${ }^{4}$ On the basis of an evaluation of 256 molecules in the AFM images including the image in Figure S5A, the number-average molecular length $\left(L_{\mathrm{n}}=203 \mathrm{~nm}\right)$, the weight-average molecular length $\left(L_{\mathrm{w}}=290 \mathrm{~nm}\right)$, and the length distribution $\left(L_{\mathrm{w}} / L_{\mathrm{n}}=\right.$ 1.43) of poly-1-HCl were estimated (Figure S5B). These values were measured without compensation for the tip radius of curvature (ca. $10 \mathrm{~nm}$ ), and so the measured values were overestimated because of the broadening effect of the tip. However, the tip broadening played a minor role in the determination of the contour length of the rodlike species. ${ }^{8}$ Polymer lengths were measured using the NIH Image program, developed at the National Institutes of Health (available on the Internet at http://rsb.info.nih.gov/nih-image/). The number-average molecular weight was then calculated to be $2.36 \times 10^{5}$ from the equation, $M_{\mathrm{n}}=\left(L_{\mathrm{n}} / h\right) \times M_{0}$, where $h$ and $M_{0}$ represent the unit height $(0.2162 \mathrm{~nm})$ estimated from the X-ray analysis of poly-1-HCl and the molecular weight (251.79) of the repeating unit of poly-1-HCl, respectively. 
A

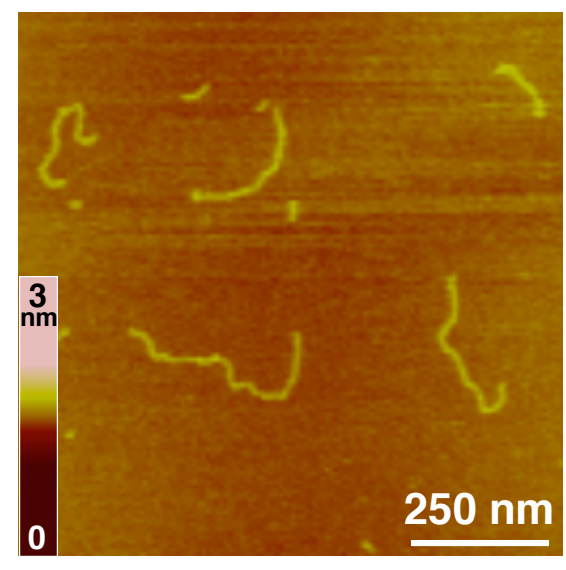

B

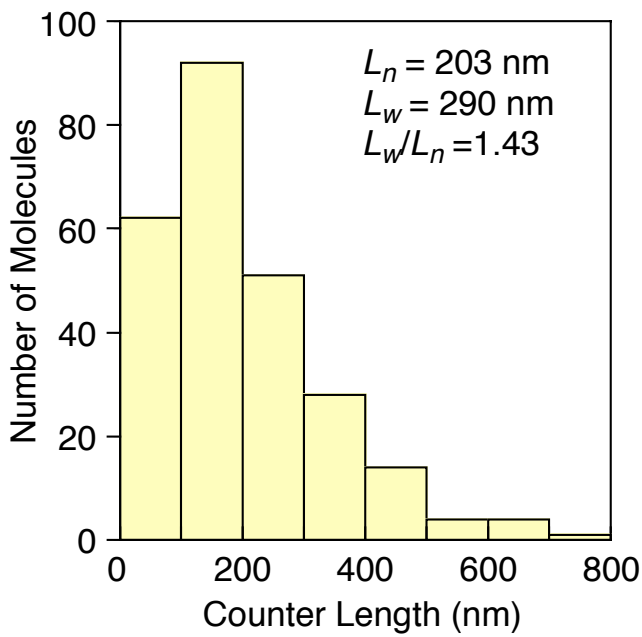

Figure S5. (A) The typical tapping-mode AFM height image of poly-1-HCl on mica. (B) Histogram of the molecular length distribution of poly-1-HCl obtained from the AFM images. Based on of an evaluation of 256 molecules, $L_{\mathrm{n}}, L_{\mathrm{w}}$, and $L_{\mathrm{w}} / L_{\mathrm{n}}$ were estimated.

\section{Phase Boundary Concentration Measurements}

The cholesteric and nematic liquid crystalline poly-1-HCl $(20.9 \mathrm{mg})$ solutions were prepared in Mili-Q water (10 wt \%) in the presence of 0.1 equiv of $(S)-2$ and 0.1 equiv of $\mathrm{NaCl}$, respectively, in 3-mL test tubes. $\mathrm{NaCl}$ was used to reduce the effect of the salt concentration on the phase boundary concentration measurement for the nematic LC poly1-HCl. The poly-1-HCl formed a one-handed helical structure in the presence of 0.1 equiv of $(S)-2$ in dilute solution, thus showing an almost full ICD. These concentrated solutions were then gradually diluted with Mili-Q water until the optical anisotropy disappeared during polarizing optical microscopy. The concentration where the optical anisotropy disappeared, namely the isotropic-anisotropic LC phase boundary concentration was taken as $C_{i}$. The isotropic-nematic LC phase boundary concentration $\left(C_{i-n}\right)$ in the presence of 0.1 equiv of $\mathrm{NaCl}$ and the isotropic-cholesteric LC phase boundary concentration $\left(C_{i-c}\right)$ in the presence of 0.1 equiv of $(S)-2$ were 0.0784 and $0.0700 \mathrm{~g} / \mathrm{cm}^{3}$, respectively. 


\section{Persistence Length Measurements}

If the persistence length $q$, the molar mass per unit contour length $M_{\mathrm{L}}\left(=M_{0} / h=1165\right.$ $\mathrm{nm}^{-1}$ ), and the isotropically averaged effective molecular diameter ${ }^{9} d_{\text {eff }}$ are given, the theory of Khokhlov and Semenov ${ }^{10-12}$ allows calculating $C_{i}$ using

$$
C_{i}=\left[\left(3.34+11.94 N+6.34 N^{2}\right) /\{(1+0.5868 N) N\}\right]\left(d_{e f f} / 2 q\right) /\left\{\pi\left(d_{e f f} / 2\right)^{2} N_{\mathrm{A}} / M_{\mathrm{L}}\right\}
$$

where $N$ and $N_{\mathrm{A}}$ are the Kuhn statistical segment number defined by $N=M_{\mathrm{w}} / 2 q M_{\mathrm{L}}$ and Avogadro's constant, respectively. Although eq 1 uses the second virial approximation, ${ }^{10-12}$ the higher virial terms are not very important in $C_{i}$ if $C_{i}$ is low enough. ${ }^{13-15}$

According to Stroobants et al., ${ }^{16} d_{\text {eff }}$ can be calculated using the equation

$$
d_{e f f}=\kappa^{-1}\left\{\ln \left(2 \pi v_{e f f}^{2} Q / \kappa\right)+\gamma+\ln 2-1 / 2\right\}
$$

where, $\kappa$ is the Debye screening length, $v_{\text {eff }}$ is the effective linear charge density, $Q$ is the Bjerrum length $\left(=0.714 \mathrm{~nm}\right.$ in $25{ }^{\circ} \mathrm{C}$ water $)$, and $\gamma$ is Euler's constant $(=0.5772)$. The value of $\kappa$ may be calculated by ${ }^{14,15}$

$$
\kappa^{2}=8 \pi Q N_{\mathrm{A}}\left(C_{s}+\Gamma z_{p} C_{i} / M_{\mathrm{w}}\right)
$$

with the molar concentration $C_{s}$ of the added salt, the Donnan salt exclusion coefficient $\Gamma$, and the valence $z_{p}$ of the polyion. According to the Manning theory ${ }^{17}$ of polyelectrolytes, we write $\Gamma$ as $1 /(4 \xi)$, where $\xi$ is the Manning charge density parameter. Since we have checked the full ionization of poly-1-HCl in the solution by $\mathrm{pH}$ measurements, we can calculate $z_{p}$ and $\xi$ by $z_{p}=M_{\mathrm{w}} / M_{0}$ and $\xi=Q / h$.

Using the Philip-Wooding solution ${ }^{18}$ of the Poisson-Boltzmann equation for the charged cylinder, Stroobants et al. ${ }^{16}$ proposed calculating $v_{\text {eff }}$ using

$$
v_{\text {eff }}=1 /\left\{2 Q K_{0}\left(R^{*}\right)\right\}
$$

Here, $K_{0}$ is the zero-order modified Bessel function of the second kind, and $R^{*}$ is given as the solution of 


$$
1+(\beta / 2) \cot \left[(\beta / 2) \ln \left(\kappa d / 2 R^{*}\right)+\sin ^{-1}\left\{\beta /\left(e^{1 / 2} R^{*}\right)\right\}\right]=\xi
$$

in case of eq 5 of the Philip-Wooding solution, ${ }^{18}$ where $\beta=2.65$ and 2.59 for the nematic

and cholesteric systems, respectively, and the molecular diameter $d$ is estimated to be 1.918 $\mathrm{nm}$ from a model of poly-1. We note that eq 5 has two solutions of $R^{*}$ for our system. From the criterion that the solution of $R^{*}$ in case of eq 5 must be connected to the solution in case of eq 3 with a decreasing $\xi$, the small $R^{*}$ is a suitable solution.

We have searched for values of $q$ leading to the best fit of the experimental $C_{i-n}$ and $C_{i-c}$ for the nematic and cholesteric systems, respectively, to the theoretically calculated values from the above equations. It is noted that eq 3 contains $C_{i}$ so that the calculation of $C_{i}$ must be iteratively made to produce a consistent $C_{i}$ in eqs 1 and 3 . The values of $q$ determined by this method were 26.2 and $28.0 \mathrm{~nm}$ for the nematic and cholesteric systems, respectively.

\section{X-ray Measurements (Figures 3, S6, S7, and S8)}

Oriented poly-1-HCl films were prepared for the X-ray analyses by shearing a uniaxially LC nematic and cholesteric water solutions of poly-1-HCl cast on a glass plate. After drying in air, the oriented poly-1-HCl films were floated off from the glass substrates onto an acetone surface, carefully collected, and then dried. Any trace amounts of residual water were not detected by elemental analysis. Several uniaxially oriented thin and rectangle-shaped poly-1- $\mathrm{HCl}$ films of ca. $10 \mathrm{~mm}$ length, $1.5 \mathrm{~mm}$ width, and $0.02 \mathrm{~mm}$ thickness were prepared and piled up parallel to each other for the X-ray measurements. In the same way, the oriented poly-1-HCl-(S)-2 films were prepared from a cholesteric LC solution of poly-1- $\mathrm{HCl}$ with 0.1 equiv of $(S)-\mathbf{2}$ in water. X-ray photographs were taken at ambient temperature $\left(20-25{ }^{\circ} \mathrm{C}\right)$ from the edge-view position with a beam parallel to the film surface, without any heat treatment of the samples because poly-1- $\mathrm{HCl}$ is thermally unstable and cis-to-trans isomerization took place at high temperature $\left(>100{ }^{\circ} \mathrm{C}\right)$, although 
the poly-1-HCl is quite stable in solution and in the solid state at ambient temperature for a long time and the diffraction patterns did not change after ca. one month at ambient temperature $\left(20-25^{\circ} \mathrm{C}\right)$.

Figure S6 shows the X-ray diffraction patterns of an oriented optically inactive poly-1$\mathrm{HCl}$ film (Figure S6A) and an optically active, single-handed helical poly-1-HCl- $(S)-2$ film $([(S)-2] /[$ poly-1-HCl] $=0.1)($ Figure S6B) with different ranges of sensitivities to show both the strong and weak reflections (see also Figure 3 for comparison), where the main layer lines have been indicated and the indices of the main reflections have been labeled.
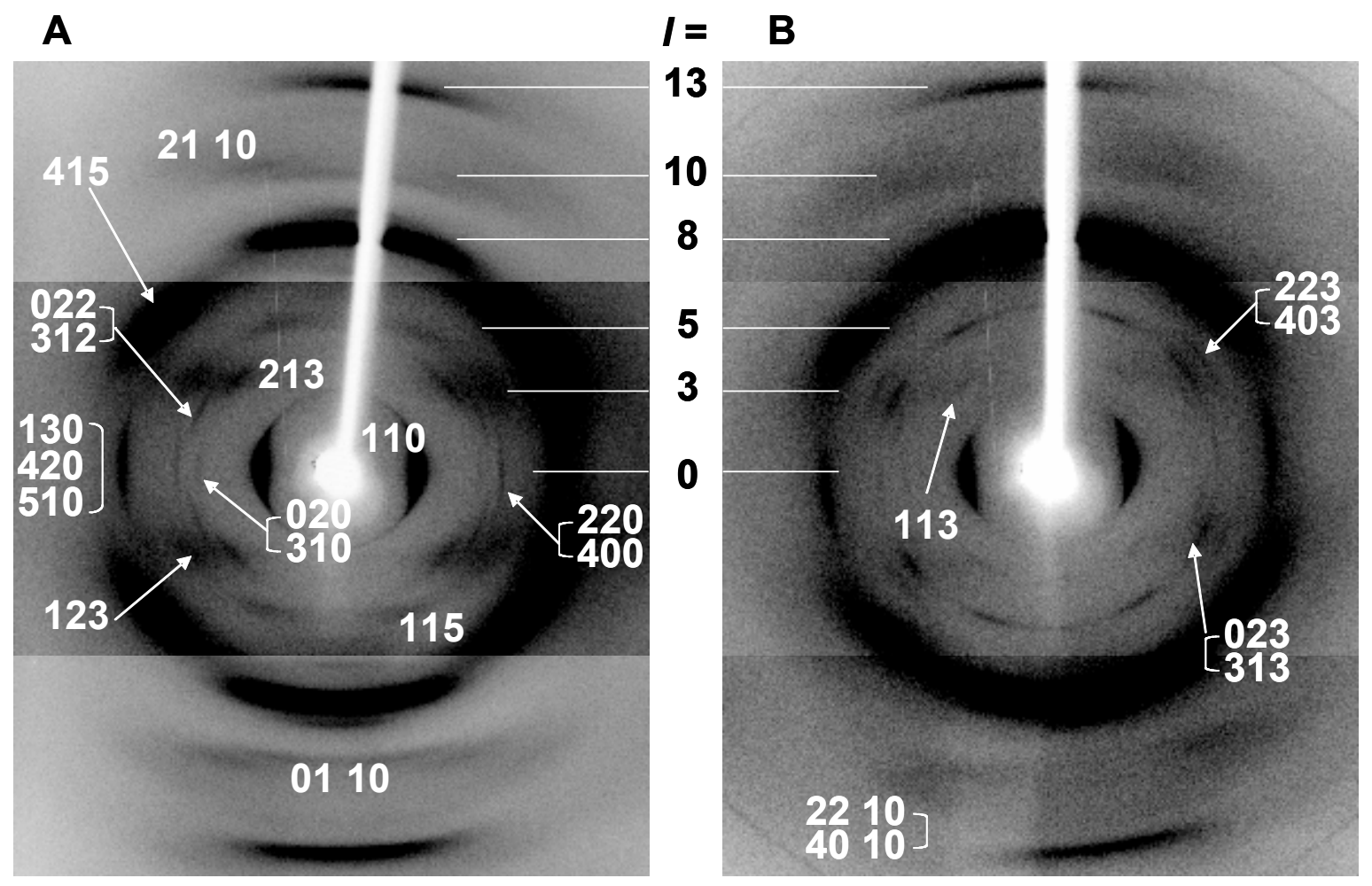

Figure S6. The X-ray diffraction patterns of an oriented optically inactive poly-1- $\mathrm{HCl}$ film (A) and an optically active, single-handed helical poly-1-HCl- $(S)-2$ film $([(S)-2] /[$ poly-1$\mathrm{HCl}]=0.1)(B)$ with different ranges of sensitivities; the representative layer lines and the main reflections are labeled. 
Figure S7 shows the flow charts for the determination processes of the unit cell (A) and the helical structure of poly-1-HCl (B) on the basis of the X-ray diffraction patterns (Figure S6) together with the density measurement results and the geometrical analyses using Miyazawa's equation (see below).

(A)

\section{Process}

-Analysis of a two-dimensional (2-D) lattice from equatorial reflections

-Determination of the fiber period $(=c=49.74 \AA$ )

-Index of all the reflections

1st trial

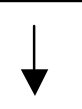

- Based on a 2-D hexagonal lattice of $a=19.84 \AA$, 3rd and 5th layer line reflections cannot be indexed.

\section{2nd trial}

-Based on a larger 2-D orthogonal lattice of $a=34.36 \AA$, $b=19.84 \AA$, all the reflections can be indexed.

(B)

Density measurement

- Four chains per unit cell, and 23 monomeric units in the fiber period

Search for the relatively strong layer lines corresponding to first-order Bessel functions

-10 th and 13th layer lines

$\cdot 23 / 10$ helix

It has also been confirmed that a $23 / 10$ helix is the most suitable conformation according to Miyazawa's equation.

Figure S7. The determination processes of the unit cell for poly-1-HCl (A) and the helical structure of poly-1- $\mathrm{HCl}(\mathrm{B})$ 
Although the most probable helical conformation of poly-1 is considered to be the $23 / 10$ helix on the basis of the X-ray diffraction analyses and the density measurement results, the meridional reflection on the 23 rd layer line $(2.16 \AA)$ corresponding to the unit height $(h)$ could not be detected. In order to justify the validity of this $23 / 10$ helix model, we explored the geometrically allowed helical conformations of poly-1 using Miyazawa's equation. ${ }^{19}$ According to Miyazawa, helical conformations of infinite (periodic) polymer chains can be described by the helical parameters including the unit height $(h)$, the number of repeating units $(n)$ per one helical turn, and the backbone dihedral angle if the internal coordinates, such as the bond lengths, the bond angles, and the internal torsion angles are given. The internal coordinates were determined by $a b$ initio quantum chemical calculations as follows: the bond lengths $(\mathrm{C}=\mathrm{C}: 1.374 \AA$ and $\mathrm{C}-\mathrm{C}: 1.466 \AA)$ and the bond angles $(\mathrm{C}-\mathrm{C}=\mathrm{C}$ : $128.8^{\circ}$ and $\mathrm{C}=\mathrm{C}-\mathrm{C}: 121.3^{\circ}$ ), and the double bond geometry and the main chain dihedral angle defined by $-\mathrm{C}-\mathrm{C}=\mathrm{C}-\mathrm{C}$ - were fixed to $c i s$ and $0^{\circ}$, respectively. The dihedral angle $(\phi)$ of a single bond from planarity $(-\mathrm{C}=\mathrm{C}-\mathrm{C}=\mathrm{C}-)$ can be varied from 0 to $180^{\circ}(n=2)$. The helical parameters $h$ and $n$ were then calculated for each poly-1 conformation defined as a function of $\phi$ according to Miyazawa's equation, which allows geometrically possible helical conformations of poly-1 as a function of $h$ and $n$ (green solid line in Figure S8); in other words, helical conformations away from the green line can be excluded due to a geometrical reason. This profile was hardly changed when the reported bond lengths $(\mathrm{C}=\mathrm{C}$ : $1.35 \AA$ and $\mathrm{C}-\mathrm{C}: 1.46 \AA$ ) and bond angles $\left(\mathrm{C}-\mathrm{C}=\mathrm{C}: 125.1^{\circ}\right.$ and $\left.\mathrm{C}=\mathrm{C}-\mathrm{C}: 125.1^{\circ}\right)$ for a nonsubstituted polyacetylene were employed as the internal coordinates. ${ }^{20}$

We then calculated the possible helical forms of poly-1 defined by the helical parameters $h$ and $n$ (= $m$ residues per $l$ turns) including the 23 unit /10 turn (23/10) helix, where the number of turns $(l)$ was taken from the layer line reflections $(l=7,8,9,10$, and 13) in Table 2 and the number of residues $(m)$ was selected so as to satisfy the X-ray diffraction 
data in Table 2. The results are plotted as circles with different colors in Figure S8, where the number represents the residues $(m)$. Among all the possible helical forms plotted in Figure S8, the geometrically allowed helical conformations that fit the green line were 23/10, 27/10, and 38/13 helices. However, the calculated densities for the 27/10 and 38/13 helical forms of poly-1-HCl are 1.332 and $1.875 \mathrm{~g} / \mathrm{cm}^{3}$, respectively, which are much higher than that of the observed density $\left(1.142 \mathrm{~g} / \mathrm{cm}^{3}\right)$, while the calculated density $(1.135$ $\mathrm{g} / \mathrm{cm}^{3}$ ) for the $23 / 10$ helix agrees well with the observed density. Consequently, the 23/10 helix appears to be the most plausible helical conformation for the poly-1 (Figure 3C).

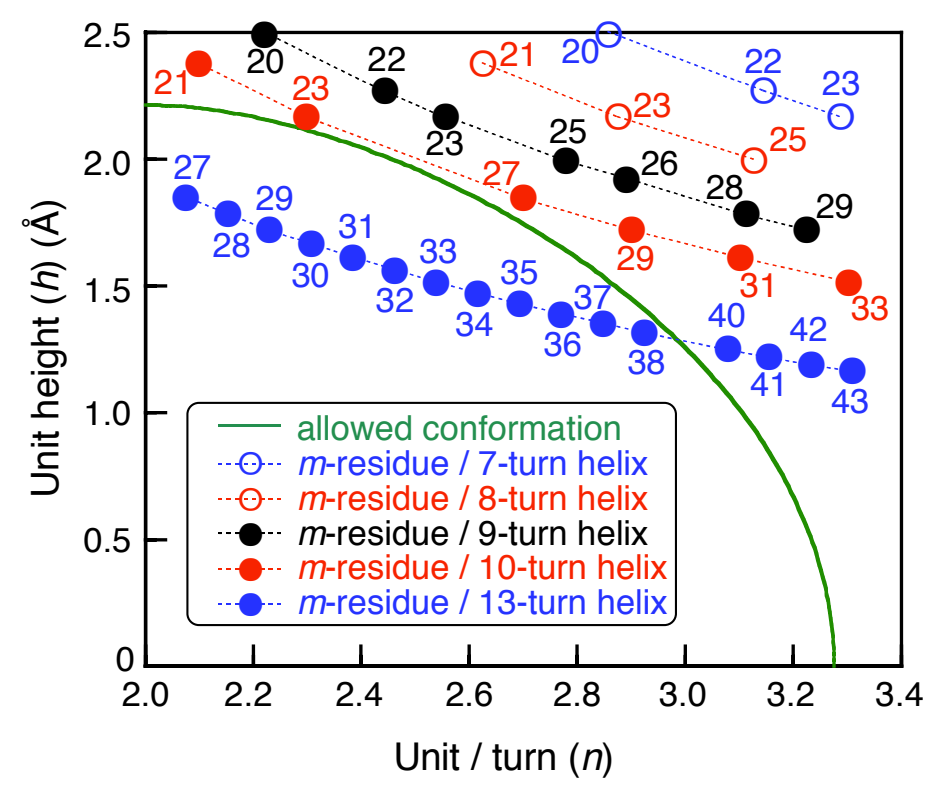

Figure S8. The geometrically allowed helical conformation (green solid line), namely the relationship between the number of repeating units $(n)$ per one turn and the unit height $(h)$ calculated from Miyazawa's equation. The circles show the candidates for the helical forms derived from the X-ray results (Table 2), where the number $(m)$ represents the number of the residues per $l$ turns and the number of turns $(l)$ was taken from the layer line reflections $(l=7,8,9,10$, and 13) in Table 2. 


\section{Molecular Modeling of Poly-1 (Figure 3C)}

Molecular modeling and molecular mechanics calculations were conducted using the Compass force field ${ }^{21}$ as implemented in the MS Modeling software (version 3.1, Accelrys Inc., San Diego, CA) operated using a PC running under Windows ${ }^{\circledR}$ XP. The polymer model of poly-1 (23 repeating monomer units) was constructed using a Polymer Builder module in MS Modeling software based on the X-ray analysis results. The starting main chain conformation ( 23 unit / 10 turn helix) of a poly-1 model was defined by the bond lengths $(\mathrm{C}=\mathrm{C}: 1.374 \AA$ and $\mathrm{C}-\mathrm{C}: 1.466 \AA)$, the bond angles $\left(\mathrm{C}=\mathrm{C}-\mathrm{C}: 124.8^{\circ}\right.$ and $\mathrm{C}-\mathrm{C}=\mathrm{C}$ : $128.8^{\circ}$ ), and the dihedral angles ( $\mathrm{C}-\mathrm{C}=\mathrm{C}-\mathrm{C}: 0^{\circ}$ (cis) and $\mathrm{C}=\mathrm{C}-\mathrm{C}=\mathrm{C}: 140.3^{\circ}$ (transoid)). These initial parameters were set on the basis of the calculated structure of a cis-transoidal phenylacetylene heptamer using the density functional theory (DFT) at the B3LYP level ${ }^{22,23}$ and the 6-31G basis set in Gaussian 03 program (Gaussian, Inc., Pittsburgh, PA). ${ }^{24}$ The bond lengths and bond angle $(\mathrm{C}-\mathrm{C}=\mathrm{C})$ of the central monomer unit of the optimized heptamer were employed in order to avoid any influence by the end groups. Although the calculated bond angle $(\mathrm{C}=\mathrm{C}-\mathrm{C})$ obtained by $\mathrm{DFT}$ was $121.3^{\circ}$, this value was changed to $124.8^{\circ}$ so as to satisfy the X-ray result (2.3 unit/turn and 2.162(5) $\AA$ as the unit height). This bond angle is similar to that $\left(125.1^{\circ}\right)$ of the reported value for a nonsubstituted polyacetylene. The dihedral angles were then estimated using Miyazawa's equation. ${ }^{19}$ These geometrical parameters for the helical poly-1 backbone structure were fixed during the following force field optimization. The dielectric constant was set to 1.0. The calculation was used with setup parameters that include a $10.0 \mathrm{kcal} \mathrm{mol}^{-1} \AA^{-1}$ final convergence for minimization. Geometry optimizations were carried out without any cutoff in two steps. First, the starting conformation was subject to the steepest decent optimization in order to eliminate the worse steric conflicts. Second, subsequent optimization until the convergence using a conjugate gradient algorithm was performed. The final poly-1 model as shown in 
Figure $3 \mathrm{C}$ was reconstructed by adopting the geometry of the central monomer unit of the optimized poly-1 structure to avoid the end-group effect.

\section{References}

S1. (a) Yashima, E.; Maeda, Y.; Okamoto, Y. Chem. Lett. 1996, 955-956. (b) Yashima, E.; Maeda, Y.; Matsushima, T.; Okamoto, Y. Chirality 1997, 9, 593-600.

S2. Maeda, K.; Takeyama, Y.; Sakajiri, K.; Yashima, E. J. Am. Chem. Soc. 2004, 126, $16284-16285$

S3. Nagai, K.; Maeda, K.; Takeyama, Y.; Sakajiri, K.; Yashima, E. Macromolecules 2005, $38,5444-5451$.

S4. (a) Prokhorova, S. A.; Sheiko, S. S.; Möller, M.; Ahn, C.-H.; Percec, V. Macromol. Rapid Commun. 1998, 19, 359-366. (b) Thomas, B. N.; Corcoran, R. C.; Cotant, C. L.; Lindemann, C. M.; Kirsch, J. E.; Persichini, P. J. J. Am. Chem. Soc. 1998, 120, 12178-12186. (c) Börner, H. G.; Beers, K.; Matyjaszewski, K.; Sheiko, S. S.; Möller, M. Macromolecules 2001, 34, 4375-4383. (d) Cornellissen, J. J. L. M.; Graswinckel, W. S.; Adams, P. J. H. M.; Nachtegaal, G. H.; Kentgens, A. P. M.; Sommerdijk, N. A. J. M.; Nolte, R. J. M. J. Polym. Sci. Part A: Polym. Chem. 2001, 39, 4255-4264. (e) Sakurai, S.; Kuroyanagi, K.; Nonokawa, R.; Yashima, E. J. Polym. Sci., Part A: Polym. Chem. 2004, 42, 5838-5844.

S5. (a) Simionescu, C. I.; Percec, V.; Dumitrescu, S. J. Polym. Sci: Polym. Chem. Ed. 1977, 15, 2497-2509. (b) Simionescu, C. I.; Percec, V. Prog. Polym. Sci. 1982, 8, 133-214. (c) Furlani, A.; Napoletano, C.; Russo, M. V.; Feast, W. J. Polym. Bull. 1986, 16, 311-317. (d) Matsunami, S.; Kakuchi, T.; Ishii, F. Macromolecules 1997, 30, 1074-1078. (e) Kishimoto, Y.; Eckerle, P.; Miyatake, T.; Kainosho, M.; Ono, A.;

Ikariya, T.; Noyori, R. J. Am. Chem. Soc. 1999, 121, 12035-12044. (f) Percec, V.; Rudick, J. G. Macromolecules 2005, 38, 7241-7250.

S6. (a) Shirakawa, H.; Ito, T.; Ikeda, S. Polym. J. 1973, 4, 469-462. (b) Tabata, M.; 
Tanaka, Y.; Sadahiro, Y.; Sone, T.; Yokota, K.; Miura, I. Macromolecules 1997, 30, 5200-5204.S6.

S7. Vesenka, J.; Manne, S.; Giberson, R.; Marsh, T.; Henderson, E. Biophys. J. 1993, 126, 992-997.

S8. $\quad$ Samorí, P.; Francke, V.; Müllen, K.; Rabe, J. P. Chem. Eur. J. 1999, 5, 2312-2317.

S9 Onsager, L. Ann. N. Y. Acad. Sci. 1949, 51, 627-659.

S10. Khokhlov, A. R.; Semenov, A. N. Physica A 1981, 108, 546-556.

S11. Khokhlov, A. R.; Semenov, A. N. Physica A 1982, 112, 605-614.

S12. Itou, T.; Teramoto, A. Macromolecules 1988, 21, 2225-2230.

S13. Sato, T.; Kakihara, T.; Teramoto, A. Polymer 1990, 31, 824-828.

S14. Sato, T.; Teramoto, A. Physica A 1991, 176, 72-86.

S15. Inatomi, S.; Jinbo, Y.; Sato, T.; Teramoto, A. Macromolecules 1992, 25, 5013-5019.

S16. Stroobants, A.; Lekkerkerker, H. N. W.; Odijk, Th. Macromolecules 1986, 19, 22322238.

S17. Mannig, G. S. J. Chem. Phys. 1969, 51, 924-933.

S18. Philip, J. R.; Wooding, R. A. J. Chem. Phys. 1970, 52, 953-959.

S19. Miyazawa, T. J. Polym. Sci. 1961, 55, 215-231.

S20. Chien, J. C. W.; Karasz, F. E.; Shimamura, K. Macromolecules 1982, 15, 1012-1017.

S21. Sun, H. J. Phys. Chem. B 1998, 102, 7338-7364.

S22. Becke, A. D. J. Chem. Phys. 1993, 98, 5048-5652.

S23. Lee, C.; Yang, W.; Parr, R. G. Phys. Rev. B 1988, 37, 785-789.

S24. Frisch, M. J.; Trucks, G. W.; Schlegel, H. B.; Scuseria, G. E.; Robb, M. A.; Cheeseman, J. R.; Montgomery, J. A., Jr.; Vreven, T.; Kudin, K. N.; Burant, J. C.; Millam, J. M.; Iyengar, S. S.; Tomasi, J.; Barone, V.; Mennucci, B.; Cossi, M.; Scalmani, G.; Rega, N.; Petersson, G. A.; Nakatsuji, H.; Hada, M.; Ehara, M.; Toyata, K.; Fukuda, R.; Hasegawa, J.; Ishida, M.; Nakajima, T.; Honda, Y.; Kitao, O.; Nakai, H.; Klene, M.; Li, X.; Knox, J. E.; Hratchian, H. P.; Cross, J. B.; Adamo, C.; Jaramillo, J.; Gomperts, R.; Stratmann, R. E.; Yazyev, O.; Austin, A. J.; Cammi, R.; 
Pomelli, C.; Ochterski, J. W.; Ayala, P. Y.; Morokuma, K.; Voth, G. A.; Salvador, P.; Dannenberg, J. J.; Zakrzewski, V. G.; Dapprich, S.; Daniels, A. D.; Strain, M. C.; Farkas, O.; Malick, D. K.; Rabuck, A. D.; Raghavachari, K.; Foresman, J. B.; Ortiz, J. V.; Cui, Q.; Baboul, A. G.; Clifford, S.; Cioslowski, J.; Stefanov, B. B.; Liu, G.; Liashenko, A.; Piskorz, P.; Komaromi, I.; Martin, R. L.; Fox, D. J.; Keith, T.; AlLaham, M. A.; Peng, C. Y.; Nanayakkara, A.; Challacombe, M.; Gill, P. M. W.; Johnson, B.; Chen, W.; Wong, M. W.; Gonzalez, C.; Pople, J. A. Gaussian 03; Gaussian, Inc.: Pittsburgh, PA, 2003. 